\title{
Health care expenditure in the Islamic Republic of Iran versus other high spending countries
}

\author{
Bahman Khosravi ${ }^{1,2}$, Shahin Soltani ${ }^{3}$, Javad Javan-Noughabi ${ }^{4}$, Ahmad Faramarzi $^{2 *}$ \\ Received: 25 June 2016 \\ Published: 6 Dec 2017
}

\begin{abstract}
Background: In all countries, health expenditures are a main part of government expenditure, and governments try to find policies and strategies to reduce this expenditure. Overall expenditure index has been raised 30 times during the past 20 years in Iran, while in the health sector, the growth in health expenditures index has been 71 times. The present study aimed at examining health care expenditure in the Islamic Republic of Iran versus other high spending countries.

Methods: A comparative panel study was conducted in selected countries with the high mean of health expenditure per capita. Data were collected from the WORLD BANK. Out- of- pocket (OOP), health expenditure per capita, public and private health expenditure, and total health expenditure were compared among the selected counties.

Results: Iran has the lowest health expenditure per capita compared to other countries and the USA has the highest health expenditures per capita. In Iran, out- of- pocket expenditure, with more than $50 \%$, was the most cost, while in Luxembourg it was the least cost during 2004 to 2014, with less than $12 \%$.

Conclusion: Our findings revealed that politicians and health care executives should find a stable source to finance the health system. Stable sources of financing lead to having a steady trend in health expenditure.
\end{abstract}

Keywords: Health Expenditure, Iran, Per Capita, Out of Pocket

Copyright $@$ Iran University of Medical Sciences

Cite this article as: Khosravi B Soltani Sh, Javan Noughabi J, Faramarzi A. Health care expenditure in the Islamic Republic of Iran versus other high spending countries. Med J Islam Repub Iran. 2017 (6 Dec);31:71. https://doi.org/10.14196/mjiri.31.71

\section{Introduction}

The rapid and rising growth of health care expenditures has created great concern for the governments and people around the world and has become one of the main concerns of managers and decision-makers in health systems $(1,2)$. Continued expansion of new and expensive health technologies, rising expectations of the societies, increase of chronic diseases, and age of populations have been reasons for the growth of health expenditures $(2,3)$. Cutler argues that technological advances can increase life expectancy, thus causing the growth of health care costs (4). Also, Hall and Jones demonstrated that increase in income levels can cause rapid growth in health care spending

Corresponding author: Ahmad Faramarzi, ahmadfaramarzi97@yahoo.com

1. Zabol University of Medical Sciences, Zabol, Iran.

2.Department of Health Management and Economics, School of Public Health, Tehran University of Medical Sciences, Tehran, Iran

3. Research Center for Environmental Determinants of Health, Kermanshah University of Medical Sciences, Kermanshah, Iran.

4. Health Management and Economics Research Center, Iran University of Medical Sciences, Tehran, Iran.
(5).There is great differentiation in the health spending among countries across the world. For example, in high income countries, health expenditure per capita is more than US\$ 3000, while in low income countries this is less than US\$ 30. Moreover, there is a great difference in health expenditures of countries, given their economic growth. Some countries spend more than $12 \%$ of their Gross Domestics Product (GDP) on health, while others spend less than $3 \%(3)$.

In all countries, heath expenditures are a large part of government costs and governments try to find policies and strategies to reduce the expenditures, and the health sector

$\uparrow$ What is "already known” in this topic:

In the last decade, health expenditure has increased dramatically in all countries of the world. No study has been conducted in order to compare health care expenditure in Iran versus other high spending countries.

$\rightarrow$ What this article adds:

In Iran, health expenditure per capita has been the lowest in comparison to selected countries, but out of pocket has been higher than those countries. 
is no exception. Due to responsiveness, governments cannot reduce health expenditure significantly, thus, they seek suitable ways to resolve the problem (6). One of these strategies is the appropriate financing of the health sector so that each country could decide about a final financing strategy. Usually, countries use several ways to finance health system such as general revenue, social insurances, private insurances, out- of- pocket (OOP), community based health financing, and external sources (7). Qatar, compared to other countries, spent the lowest cost on health and devoted only $1.8 \%$ of GDP on health. Health financing in Qatar is mainly based on out- of- pocket (8). On the other hand, the USA has the first rank for health expenditures and the highest health expenditures per capita among OECD countries so that in 2011 health expenditure per capita was US\$ 7212 in the USA. Also, USA has devoted the highest GDP on health but in this country, out- of- pocket is higher than other OECD countries (9).

Like other countries, Iran's health system faces the challenge of the expenditures growth. Overall expenditure index has been raised 30 times during the past 20 years in Iran, while in the health sector, the growth in health expenditures index has been 71 times. This issue confronted Iran's health system with many problems in different aspects (10). Financing in Iran's health system includes a mix of general revenue, social insurance, private insurance, and out- of- pocket. Given that private or public insurances cover more than $90 \%$ of Iranians, but studies show that more than $50 \%$ of health expenditures have been paid by out- of- pocket (11).

Considering the above mentioned points, it can be stated that health spending varies from country to country and each country spends a different amount of GDP on health based on its circumstances. We selected a country with the highest health spending per capita in several regions of the world health organization to examine health care expenditure in the Islamic Republic of Iran versus countries with high spending.

\section{Methods}

This comparative panel study investigated health expenditures in the selected countries. In this study, in accordance with WHO categorization, countries were divided into 6 regions. Then, in each region, the average health expenditure per capita was calculated for all countries during 2004 to 2014, and a country with highest mean was selected. For instance, in Southeast Asia, consisting 11 countries, Maldives was selected. In the West Pacific region, there were 37 countries, among which Australia was selected. Europe region consisted of 55 countries and Luxembourg had the highest heath expenditure per capita in that region. The America region included 47 countries, and the USA was selected among them. In the Eastern Mediterranean and Africa regions with 23 and 47 countries, respectively, Qatar and Southern Africa had the highest health expenditures per capita. Variables of the current study were selected according to the literature reviews and field investigations, and they included health expenditure per capita, total health expenditure as a percentage of GDP, out- of- pocket as a percentage of total health expenditure, public health expenditure as a percentage of total health expenditures, and private health expenditure as a percentage of GDP. Variables have been adjusted based on purchasing power parity (PPP) $(9,12$, 13). Data have been collected according to the World Bank. The World Bank publishes a report about economic performance of countries, and the collected data are available in the World Bank (14).

After determining the variables and collecting data, we compared the trends of health expenditures and the mix of these expenditures among Iran and selected countries to identify similarities and differences between the expenditures of the countries.

\section{Results}

Table 1 demonstrates the variables and their values. Health Expenditures Trend: Table 1 shows that Iran has

\begin{tabular}{|c|c|c|c|c|c|c|c|}
\hline Year & Maldives & Australia & Luxembourg & United States & Qatar & South Africa & Iran \\
\hline \multicolumn{8}{|c|}{ Health spending per person (us \$ ppp) } \\
\hline 2004 & 236 & 2933 & 6145 & 6369 & 1563 & 380 & 145 \\
\hline 2008 & 613 & 4410 & 8303 & 7786 & 1555 & 441 & 315 \\
\hline 2011 & 589 & 6368 & 8333 & 8523 & 1716 & 686 & 545 \\
\hline 2014 & 1165 & 6031 & 8137 & 9402 & 2106 & 570 & 350 \\
\hline \multicolumn{8}{|c|}{ Total health spending, \% GDP } \\
\hline 2004 & 5.88 & 8.57 & 8.20 & 15.13 & 3.60 & 7.92 & 5.88 \\
\hline 2008 & 9.3 & 8.78 & 7.33 & 16.02 & 1.87 & 7.74 & 6.28 \\
\hline 2011 & 8.11 & 9.19 & 7.34 & 17.05 & 1.92 & 8.61 & 7.12 \\
\hline 2014 & 13.73 & 9.42 & 6.93 & 17.14 & 2.18 & 8.79 & 6.89 \\
\hline \multicolumn{8}{|c|}{ Out- of- pocket share of total health spending (\%) } \\
\hline 2004 & 23.2 & 18.1 & 11.6 & 13.3 & 15.8 & 10.84 & 55.2 \\
\hline 2008 & 18.3 & 17.9 & 9.1 & 12.5 & 16 & 8.4 & 53.5 \\
\hline 2011 & 25.2 & 17.9 & 10.5 & 11.7 & 13.8 & 6.9 & 55.5 \\
\hline 2014 & 18.2 & 18.8 & 10.6 & 11 & 6.8 & 6.4 & 47.8 \\
\hline \multicolumn{8}{|c|}{ Public health expenditure, $\%$ total health expenditure } \\
\hline 2004 & 65.8 & $66.7^{1}$ & 84.8 & 44.2 & 84.1 & 40.5 & 38 \\
\hline 2008 & 75.5 & 67.4 & 88.4 & 45.9 & 83.9 & 46.4 & 38.7 \\
\hline 2011 & 69.1 & 68.6 & 85.2 & 47.3 & 78.1 & 47.9 & 34.7 \\
\hline 2014 & 78.3 & 67 & 83.9 & 48.2 & 85.7 & 48.2 & 41.2 \\
\hline \multicolumn{8}{|c|}{ Private health expenditure, $\%$ GDP } \\
\hline 2004 & 2 & 2.8 & 1.2 & 8.4 & 0.5 & 4.7 & 3.6 \\
\hline 2008 & 2.2 & 2.8 & 0.8 & 8.6 & 0.3 & 4.1 & 3.8 \\
\hline 2011 & 2.5 & 2.8 & 1 & 8.9 & 0.4 & 4.4 & 4.6 \\
\hline 2014 & 2.9 & 3.1 & 1.1 & 8.8 & 0.3 & 4.5 & 4 \\
\hline
\end{tabular}


the lowest health expenditure per capita compared to other countries and the USA has the highest health expenditures per capita. In 2010 and 2011, the growth rate of health expenditures per capita was higher in Iran compared with other countries apart from Maldives. As displayed in Fig. 1 , the growth rate of health expenditures per capita was not equivalent in countries, but in the USA and Australia, the growth rate of health expenditures almost experienced a clear and steady trend.

As displayed in Fig. 1, the rate of growth of health expenditures per capita was more than $10 \%$ in Iran in 2005 , but the trend has decreased by 2009 and it started to increase in 2011 again so that it became to more than $15 \%$. However, the USA had the highest health expenditure per capita compared with other countries in each year, and its growth rate of health expenditure was lower than 5\% during 2004 to 2011.

During 2004 to 2014, out- of- pocket was higher in Iran compared with other countries so that in 2004 and 2014, out- of- pockets included $55 \%$ and $47 \%$ as the total health expenditure, respectively; moreover, in 2004 and 2011, $5.8 \%$ and $7.12 \%$ of GDP were spent on health sectorial in Iran, respectively.
Figure 2 displays health expenditure per capita of the selected countries according to a percentage of Iran health expenditures per capita. Apart from Maldives, health expenditure per capita in all countries was more than $100 \%$. In addition, health expenditure per capita in Qatar and the USA was $1000 \%$ and $4500 \%$ more than Iran health expenditure per capita, respectively in 2004.

\section{Discussion}

This study was conducted to compare health care expenditure in the Islamic Republic of Iran versus other high spending countries during 2004 to 2014 and to examine the trend of health expenditure per capita, OOP, and public and private health expenditures. Our finding revealed that out- of- pocket (OPP) expenditure on health was the highest in Iran among all the World Health Organization (WHO) member countries. During the study period, more than $47 \%$ of health expenditure was out-of-pocket. Studies have indicated that the share of OOP on health expenditure was small in developed countries. For example, a study conducted by Anderson et al. revealed that out- ofpocket spending per capita was less than \$1276 in OECD countries (15).

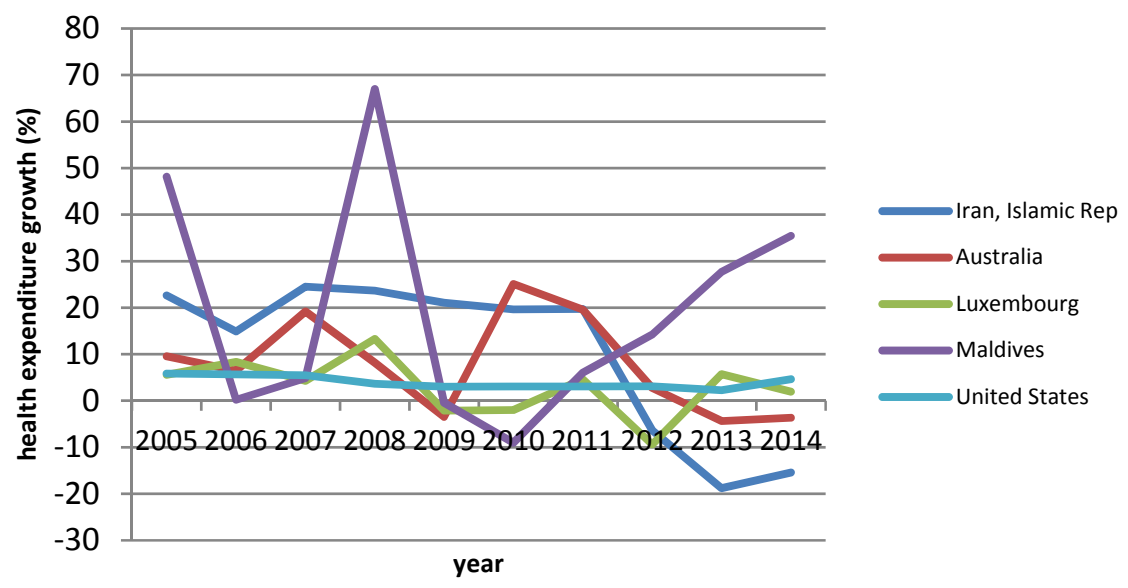

Fig. 1. The growth of health expenditure per person at the selected countries

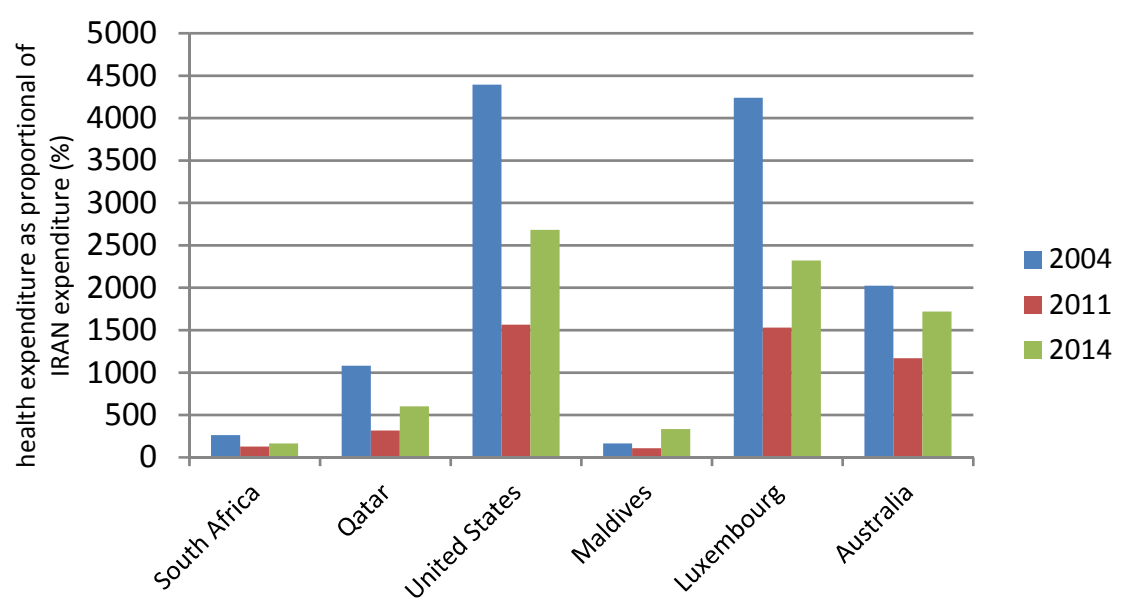

Fig. 2. Health expenditure per capita as a proportion of iran's expenditure 
In Iran, health expenditure share in Gross Domestic Product (GDP) was lower than all countries, except Qatar. Almost all WHO member countries allocated more than $5 \%$ of their GDP on the health sector. In countries we studied, the share of health expenditures as a percentage of GDP was higher than 5\%. Even in Qatar, less than 5\% of GDP were allocated to the health sector during the study period, but Qatar had the highest level of health expenditure per capita in the Eastern Mediterranean Region (16).

The share of public health expenditure in Iran was lower than other countries during 2004 to 2014, compared with the considerable high share of private health expenditure. As an example, the share of private expenditure on health sector for the years of 2004, 2008, and 2014 was about $3.6 \%, 4.6 \%$, and $4 \%$ respectively. Private health expenditure share as a percentage of GDP in Iran was higher than all other countries of our study except the USA and South Africa. Private expenditure on health for the USA was $8.4 \%$ and $8.8 \%$ in 2004 and 2014, respectively. The share of private health expenditure in Iran was relatively high, but OOP was too high. More than $47 \%$ of health expenditure was OOP over the years of this study. While in the USA the share of private health expenditure was higher than other countries, OOP was too low, less than $13 \%$ of health expenditure. In the United States, private health expenditure was included in the insurance system (17-19).

Health expenditure per capita in Iran was less than all countries of this study, and it was more than $\$ 6000$ in the United States and Luxembourg.

The growth rate of health expenditure in Iran during 2004 and 2014 did not show a regular and steady trend. For example, the growth rate of health expenditure was more than $10 \%$ in 2005 and decreased in the next years, it even became negative in 2009, and it turned again till reaching $15 \%$ in 2011 . The growth rate of health expenditure in Iran was not just irregular but it was high. However, the growth rate of health expenditure in other countries except the USA and Australia did not show a steady trend, and this could be due to resource instability in financing of the health sector. Countries with better health outcome showed a regular and steady growth of health expenditure. For instance, the growth rate of health expenditure of the USA was between $5.4 \%$ to $6.9 \%$ during 1997 to 2005 (19). Martin et al. pointed out that the health spending rate for the United States was 4\% to $12 \%$ during 1990 to 2011 (20). Thus, the high portion of growth in expenditures was associated with growth in OOP. For example, in Iran in 2005 , OOP was $55 \%$ and the growth rate of health expenditure was $22 \%$, while in 2014 , OOP was $47 \%$ and the growth in health expenditure was $-15 \%$.

The nature of various levels of health expenditure in countries is different. High level expenditure may have different causes like high inflation rate. For example, the inflation rate in the Maldives was higher than $14 \%$ in 2011. The inflation rate of Iran was $14.76 \%$ and $20.62 \%$ in 2004 and 2011, respectively, while it was less than 5\% in other countries (21).

\section{Conclusion}

According to the findings of the present study, health expenditure per capita in Iran was only higher than Maldives and it had less health expenditure per capita than other countries during 2004 to 2011. Nonetheless, direct OOP in Iran was higher than other countries. Public health expenditure share in Iran was less than other countries, but the share of private health expenditure was just less than the USA and South Africa.

\section{Conflict of Interests}

The authors declare that they have no competing interests.

\section{References}

1. Samadi AH, Homaie Rad E. Determinants of Healthcare Expenditure in Economic Cooperation Organization (ECO) Countries: Evidence from Panel Cointegration Tests. Available at SSRN 2286987. 2013.

2. Chandra A, Skinner J. Technology growth and expenditure growth in health care. J Econ Lit. 2012;50(3):645-80.

3. Kea X, Saksenaa P, Hollyb A. The determinants of health expenditure: a country-level panel data analysis. Geneva: World Health Organization. 2011

4. Cutler DM, Zeckhauser R. Extending the theory to meet the practice of insurance. Brookings-Wharton Papers on Financial Services. 2004;2004(1):1-53.

5.Hall RE, Jones CI. The value of life and the rise in health spending. National Bureau of Economic Research, 2004.

6. Veiga P. Out-of-pocket health care expenditures due to excess of body weight in Portugal. Econ Hum Biol. 2008;6(1):127-42.

7. Jenkins M. World Health Organization Report Available.

8. World Health Organization. Global Health Observatory (GHO) data. 2013. Available from: http://apps.who.int/gho/data/node.imr.

9. Lorenzoni L, Belloni A, Sassi F. Health-care expenditure and health policy in the USA versus other high-spending OECD countries. The Lancet. 2014;384(9937):83-92.

10. Central Bank of Islamic Republic of Iran. The main economic indicators [Online] 2013. Available from: www.cbi.ir.

11. Zare H, Trujillo AJ, Driessen J, Ghasemi M, Gallego G. Health inequalities and development plans in Iran; an analysis of the past three decades (1984-2010). Int J Equity Health. 2014;13(1):1.

12. McIntyre D. What healthcare financing changes are needed to reach universal coverage in South Africa?. S Afr Med J. 2012;102(6):48990.

13. Hurley J, Vaithianathan R, Crossley TF, Cobb-Clark DA. Parallel private health insurance in Australia: A cautionary tale and lessons for Canada. 2002.

14. World Health Organization Global Health Expenditure database 2016. Available from: http://apps.who.int/nha/database

15. Anderson GF, Frogner BK. Health spending in OECD countries: obtaining value per dollar. Health Aff. 2008;27(6):1718-27.

16. World health statistics Switzerland 2013. Available from: www.who. int/gho/publications/world health statistics/EN WHS2013 Full.pdf.

17. Schoen C, Osborn R, Squires D, Doty MM. Access, affordability, and insurance complexity are often worse in the United States compared to ten other countries. Health Aff. 2013;32(12):2205-15.

18. Smith JC, Medalia C. Health insurance coverage in the United States: 2013: US Department of Commerce, Economics and Statistics Administration, Bureau of the Census; 2014.

19. Marten R, McIntyre D, Travassos C, Shishkin S, Longde W, Reddy $\mathrm{S}$, et al. An assessment of progress towards universal health coverage in Brazil, Russia, India, China, and South Africa (BRICS). The Lancet. 2014;384(9960):2164-71.

20. Martin AB, Hartman M, Whittle L, Catlin A, Team NHEA. National health spending in 2012: rate of health spending growth remained low for the fourth consecutive year. Health Aff. 2014;33(1):67-77.

21. International Monetary Fund, International Financial Statistics and data files. 2016. Available from: http://data.worldbank.org/ indicator/FP.CPI.TOTL.ZG. 